\title{
The Development Analyses of Translation Theories in China
}

\author{
Xia Wang ${ }^{1, a}$ \\ ${ }^{1}$ Public Foreign Languages Teaching and Research Department, Jilin University of Finance and \\ Economics, Changchun, Jilin Province, China \\ a87696682@qq.com
}

Keywords: Translation theory, Translation, Development and History.

\begin{abstract}
Chinese translation business has a long and glorious history and tradition, as early as the Tang Dynasty there is a variety of translation activities. Translation in China since ancient times is a "cause", translation is not driven by economic interests or economic development of the product, but with the political, religious or ideological. Historically climax translation, translation theory is profound, difficult to count translator. Learn the history of translation theory today will not only help us in-depth knowledge and the development of our translation business, but also help us to inherit the fine cultural heritage of our ancestors.
\end{abstract}

\section{Introduction}

For a long time, the Chinese translation for translation's there has been controversy over some important concepts. Such as literal translation and free translation, the translation of science and art principles, the nature of translation, etc., fully reflects the complexity of translation and translation studies.

From the point of translation practice itself, it involves language is various and complex language family, have separate pronunciation, grammar, vocabulary system, reflects the respective national unique cultural spirit and thinking mode [1]. If you want to establish a guidance to any language translation practice theory is impossible. From the perspective of the subject of translation and translation studies, linguistics, philosophy, aesthetics, psychology, culture and so on each subject tangled. From the perspective of the process of translation, translation studies on each link, including author, text, reader, and even the translator can't ignore. The contradiction between the translation of this a few link brought difficulties to the translation and translation studies. Although China has accumulated rich theoretical translation theory, some scholars have been engaged in establishing translation, also named after translation[1]. A breakthrough in the short term, but will build up and philosophy, aesthetics, linguistics and culturology relatively difficult subject phase of translation.

Based on the complex and difficult of translation and translation study itself, in a certain period of silence is normal. Summarized in this paper, the development course of Chinese translation theory, find out the deficiencies, and find new breakthrough for further research.

\section{The development of China's translation theory}

Chinese translation theories, from the point of view of time, can be divided into the traditional, modern and contemporary three times [2]. In China, the traditional translation theory is to the west "modern linguistics" as the methodology of translation theory research, the concrete and can be divided into "period", "development" and "mature" and "transitional", etc [2]. The four periods witnessed China's several big translation climax respectively, Buddhist scriptures translation between Ming dynasty and early Qing, namely the eastern Han dynasty to Song dynasty and Ming Qing dynasty western translation and translation of science and technology of "May 4th" new literature translation.

Occurrence period. So-called Chinese translation theory of "period" refers to the period of traditional translation theory from scratch, it with a modest year of BC 224 for began by the method of sentence order, and in year 988, the song dynasty monk biography [2]. Translation of the article to end. Occurrence period of translation theory based on the translation of Buddhist scriptures, it to 
philosophy, in teaching, literature, music and dancing have very big effect. Occurrence period important translation theories as a modest "followed origins, don't add decoration".

Development period. Development refers to the traditional translation theory from simple to complex, from low level to high level changes in the process. This time, the social function of translation theorists begin to think, it is respectively in year 1604, the present purpose of translation press and in the year of 1894 Jianzhong's "proposed translation academy, for the above dates. The translation of this period are natural science and social science books, so as to improve the comprehensive strength of China. Development of a typical characteristic is the cooperation of Chinese and foreign translators, during the foreign translators have emerged byJacob and YiRu slightly [3].

The mature stage. Mature period refers to the improvement of the traditional translation theory, specific displays in: your translation thoughts, increasingly sophisticated proper expression method. Maturity corresponding is western translation and the "May 4th" new literature translation, marked by Yanfu's "theory of natural selection" in 1898, the representative as translation theory of "elegant writing," talk to Lin Shu's translation press hard, Jin Yuelin's "translation" and "flavor translation", "literary translation" of Zheng zhenduo, contradiction of "creation of literary translation theory", Lu Xun's "letter translation", fu lei's "spirit likeness" and "being" of Qian zhongshu, etc [3]. Mature period of translation studies has several features: translation theory tendency of literary nature, group discussion is colorful, such as Yan fu and Liang Qichao debate about translation style, language; Hu shi, Liu do agriculture such as criticism of the Yan fu and Lin shu, such as the emergence of a large number of the translator and writer, Lu xun, contradictions, such as Yan fu and Zhu,Shenghao etc.

Transition stage. Transition refers to the core of the traditional translation theory began to shift period, mainly corresponds to the establishment of new China to the linguistic translation during the study of translation theory. This time's translation theory is relatively poor.

After the 1960s. China began to get rid of the traditional translation theory research, and began the last thirty years of the introduction of western contemporary linguistic translation theories and research methods. , which mainly concerns the community of translation skills, English and bilingual before technical comparisons, the late ninety s, this way once even code text translation and translation teaching, research, and the review of translated works, caused the translation studies and criticism on the theoretical limitations and biases [4].

In the late of 1990s. Domestic began to mention of the contemporary western translation theory system about the "systems", "deconstruction" and "feminism" theory of words, even to the research of contemporary western translation theories consciously began [4]. To speak, before the $60 \mathrm{~s}$ of Chinese translation theory was sent by local Chinese translation theory, and after the sixties of Chinese translation theory research in terms of its overall is to "import" in the form of a variety of digestion.

It is pointed out that in the contemporary western translation theories explore traditional translation theory in the period of China hardly for the translation of foreign translation theory works [4]. Translation as human cultural exchanges with universality, there must be many common or regularity among them, each nation must have accumulated can inspire and draw lessons from the experience of each other, ignoring or disdain foreign translation theory does not conform to absorb all useful cultural achievements of human spirit [5]. Mr Xu Jun said: in fact, from the point of China's current translation theory research status, we know about foreign translation theory and research is not too much, but too little, too one-sided.

End of the 20th century. Translation as an independent discipline status was identified and translation to the positive efforts around the establishment of the translation, from the translation of the structure to the external structure of ontology to construct the translation system, from the Angle of macroscopic and microscopic research related problem [5]. Now although there is no a generally accepted theory system framework of translation studies, but people recognize that the development of translation theory needs to absorb the research achievements of Chinese and western translation theories, blaze new trails, to establish the complete translation. 


\section{The characteristics of the Chinese translation theory}

Throughout China's translation theory, we can easily find these familiar words "believe", "da", "elegant", "spirit likeness", and "being" and so on.

Accurate, integrity and elegant. Emerging bourgeois enlightenment thinker, yan fu in the late qing dynasty in the "theory of natural selection" introductory remarks "translation" said: "translation is fundamental: faithfulness, expressiveness and elegance. The letter has trouble, don't Gu Xin yi da, though the translation of translation, also not was still." "Letter" refers to the meaning is not back to the original, is to give an accurate translation, does not distort, no omissions, don't casually; "Up to" means not constrained to the original form, the smooth understand; "Elegant" means to classical Chinese translation [6]. Now "letter" and "da" and "elegant" three word has been said we abuse, nearly a century in modern translation theory, as a rule of translation for a long time [6]. Content is, of course, with the development of the translation theory proper made extension, relevance and change. Such as: "believe" that produced later "faithfulness", "da" corresponds to the "smooth", and the word "elegant" is endowed with new connotation, translation is not referring to the translation at first to classical Chinese, which means when choosing words properly, clear and elegant.

Vivid feeling. "Its essence and forget its thick, in them and forget it", as the name suggests, is to convey the spirit of the original, through the words meaning qu da to text. Different languages have distinguishing feature each, there are many difficult to translation, and translation is by no means coordinates when the words of "word", but a multi-level vividly [7]. Literary translation in particular. Fu lei, a famous translator life is engaged in the creation of literary translation. His literary work as divine cause, not only consider damage literature high-quality goods like to distort the truth, and will introduce a literature cannot restore itself, also think are difficult to tolerate. His deep Ming bittersweet, literary translation has remained a rigorous, serious and responsible attitude, in his own a lot of translation as, in yan fu's "letter, elegant", the other a tree signs, standard for "spirit likeness", is an important breakthrough in China's translation theories [7]. He makes the key to literary translation, the translation from the deliberate words mentioned the temper of art. More valuable is that he put the important "lifelikeness" in Chinese traditional aesthetics point of view, the introduction of translation theory, the knowledge of translation theories mentioned aesthetic category, thus widening the research field of translation theory, laid the foundation for the establishment of the later translation aesthetics. So put forward the concept of "spirit likeness" translation, marked the great progress of China's translation cause, translation theory from the generalization and abstraction to the specialization, the beginning of the embodiment.

The theory of transferred. Translation being said, it is put forward by qian zhongshu. His article is primarily Lin shu's translation criticism, criticism put forward its own views on literary translation. He said, "the highest standards of literary translation is" being ". The works from the text, text into the other country can not due to differences in language habits show traces of stiff far-fetched, and can keep the original flavor, it is in "being" [8]. He thinks that "being" is the ideal standard of literary translation, there is a distance between two languages, the translator's understanding of the original content and form is biased, therefore, translation is always a loss and damage, there will always be where the distortion and gives the translation, on the meaning or tone against or not close to the original text is inevitable.

Theory of multiple complementary. "Plural complementary theory" is a is composed of several criteria of complementary translation standard system, namely the absolute standard (original) specific standards for the highest standard (the best approximation degree) - (classification). They each has a specific function, and the translation of this theory is based on the multiple functions and the diversity of human aesthetic temperament and interest, and the readers, the translator of multilayered [8]. The standard learned the multivariate and dynamic concept, pay attention to the receiver and the role of the translator, adopt the three-dimensional way of thinking, illustrates the system internal dialectical relations, which broke the traditional translation standard unified [7].

The integrity of translation theory."Integrity of translation", namely "chapters (discourse) translation" at the core of the theory - "standard" and "standard" thought. The so-called "whole", which refers to the overall understanding, the overall message, the overall transformation of thought, 
it has changed the past the traditional principle of "sentence" [3]. The so-called discourse, namely can constitute a unified whole language texts, in the process of translation, it is relatively independent, the overall significance and art of the whole structure of the object, the so-called text translation is based on the overall meaning of the original, chapters of the overall transformation, the corresponding meaning as a whole. He proposed a word and the word "relative value", "the idea of simultaneous" and "obey the original author's thinking process," said, reveals the translation context, in the period of standard and standard of the important thought. JiaoShi overall (global) "theory" is a great contribution to the theory of text translation [2]. It has important theoretical significance and practical value. In translation practice, translators should first establish the overall concept, make corresponding meanings, and then from the top down, from big to small to investigate the significance of each part, corresponding to complete each part of the step by step.

\section{Summary}

In conclusion, Chinese traditional translation theory rooted in traditional literature and art aesthetics soil, it is based on Chinese and foreign translation practice. With Chinese characteristics it is the translation theory. It fills into account the special nature of the Chinese language, theoretical guidance for China's undeniable translation practice, so we must inherit and develop our traditional translation theory. But to the further development of translation theory, we must affirm the current translation theory research achievements at the same time, the use of achievements of modern linguistics and related disciplines has been made on the translation problems in practice only do scientific research has conducted analysis of art, so that the study of translation theory out of the silence and create a glorious 21st century.

\section{References}

[1] F.K. Chen, China History of Translation Studies, Shanghai Foreign Language Education Press, 2002, pp.41-45.

[2] Y.L. Jia, On the Chinese translation studies Characteristics, Chinese translation, 2011, pp.12-16.

[3] H.Q. Hu, Learn Chinese translation must be established on the one hundred contemporary translation, Chongqing University Press, 2014, pp.16-21.

[4] L.N. Xu, Chinese translation skills reflection and review, China Science and Technology Translation, 2008, pp.34-37.

[5] Zh.L. Hu and Y.F. Li, Development Status of translation theory, Peking University Press, 2008, pp55-58.

[6] Q.N. Liu, Translation studies Prospect, Chinese translation, 2006, pp.26-31.

[7] T.T. Zhang, Difficult reflection on the theory of silence, The Chinese translation, 2012, pp.61-65.

[8] T.X. Chu and H.H. Zhang, On the current situation of Chinese translation theory, Translation theory of our country, 2012, pp.23-27. 